\title{
Usability and usefulness of eBooks on PPCs: How students' opinions vary over time
}

\author{
Paul Lam, Shun Leung Lam, John Lam and Carmel McNaught \\ The Chinese University of Hong Kong
}

\section{An Outstanding Paper Award recipient, ascilite Melbourne 2008 Conference}

\begin{abstract}
The number of academic eBooks in university libraries is increasing. Reading digital materials such as newspapers is valued in Hong Kong; however, students' perceptions of the value of reading academic eMaterials are not well known. In this study we investigated 12 students' use of academic eBooks on mobile readers in two ways. Six students had brief introduction to eBooks and they reported their first impressions of the technology. The other six students had a 12-week eBook reading period that was closely monitored by the research team. The experiences from the two groups of students generally affirmed that the technology has potential to enhance teaching and learning in a university setting. However, the experiences (especially of the long-term users) highlight a number of challenges that need to be addressed.
\end{abstract}

\section{The rise of mobile eBooks}

Mobile learning can extend learning spaces to places beyond traditional classrooms, libraries and homes. Its potential use may be significant in Hong Kong where the ownership of mobile devices is among the highest in the world and where public transport is highly developed, providing opportunities for mobile reading. Reading digital materials such as newspapers is valued in Hong Kong (Leung, Chan \& Chan, 2003); however, the value of reading academic eMaterials in a mobile format is less known.

EBooks are "text in digital form, or digital reading material, or a book in a computer file format, or an electronic file of words and images" (Rao, 2003, pp. 86-87). EBooks are downloadable and are portable if they are stored in light portable devices such as pocket personal computers (PPCs) or smartphones.

The technology has also made possible a growth in the number of publications with shorter publishing times. The rising costs of paper books and the potential to link multimedia resources to eBooks have major impacts on the strategies used by university libraries in their support of scholarly communication (Ching, Poon \& McNaught, 2006). There are 247 entries in a list of available eBook libraries (Cavanaugh \& Cavanaugh, 2008). One of the largest collections of academic eBooks collections is NetLibrary, which at present has over 20,000 volumes of academic eBooks.

The Library of The Chinese University of Hong Kong (CUHK) has made a significant investment in licences to many leading eBook collections in the world (including 
NetLibrary). At CUHK, the use of eBooks is still not high. Since the NetLibrary system was launched in February 2006, there have been about 4,000 to 7,000 visits a month (cf. at present there are over 20,000 students and 1,100 teachers at the University). The present study is designed to provide the information needed for successful eBook take up at CUHK. The S-curve of development that is the characteristic of diffusion of innovations (Rogers, 2003) suggests that acceptance of a new technology does not undergo a stable and linear development. The level of adoption is very low at the beginning. The greatest challenge is achieving the 'growth' stage, but this is seldom achieved without careful planning and focused strategies.

The phenomenon of eBooks is quite different from the now widespread use of eJournals. The length and structure of a book, and our traditional mode of reading books, make the experience of reading a book quite different from reading a focused and relatively short article or report. It is therefore important to consider how academics and students will (or won't) adapt to reading whole books onscreen.

\section{Existing evidence about the value of academic eBooks}

There are contrary views about the value of academic eBooks. There are advocates such as Lemken (1999) who asserted that the technology should "fill the gulf between printed and digital information" (p. 4). A number of advantages have been widely claimed to be associated with this new form of technology. Hernon et al. (2006) listed advantages such as convenience, economy, portability and materials being more up to date. Shiratuddin et al. (2003) noted that students can build their own personalised digital libraries. Lam, Lam and McNaught (in press) listed the following potential advantages of using eBooks: access to more readings, remote access, searchable readings, potential links to allied multimedia resources, portable resources (a PPC can hold many books), and optimising reading time (e.g. during travel). There is also empirical evidence which indicates that, once students can connect to the technology, they enjoy it (Simon, 2002) and even read faster (Wilson, 2003).

However, there are also negative reports of the use of the technology in the academic setting. Not all students can feel comfortable with the technology. For example, some students find reading long text on a small computer screen tiring, less efficient and even 'painful' (Wilson, 2003, p. 11) compared with reading paper based text. Wilson (2003) also reported complaints about the ineffective navigational controls on eBook readers, as being "awkward, difficult or time-consuming to use" (p. 14).

The success of the eBook technology seems to rely heavily on the ease of the reading process. Malama, Landoni and Wilson (2004) found that users regard the layout of the eBook on screen as a strong motivating force; also important are the ease of navigation through a clear user interface, and a clear and logical structure to support readers' sense of place in the eBook. The optimal use of screen real estate is even more important with mobile eBooks than with desktop computers. Wilson, Landoni and Gibb (2002) used the book metaphor as a crucial design feature, including having a cover, a table of contents, a consistent and tidy typographical style, simple classification of book sections, and cues for reading progress.

Features available on eBook readers can be extensive. Apart from page turning, scrolling of text, and searching, more advanced eBook-related functionalities are constantly being developed. Wilson (2003), through collecting user feedback on using eBooks, found that users appreciate a quick and accurate search function, an 
annotation function, and the inclusion of hypertexts and dictionaries on the reader. Lam, Lam and McNaught (in press) evaluated the perceived usefulness of the functionalities on four popular eBook readers on the market which can be used on PCs and PPCs and found them, in general, to be acceptable.

\section{Research methodology}

The eBook study had a duration of 2.5 years. There were two main phases: phase 1 in the academic year 2006-07 and phase 2 from the summer (northern hemisphere) of 2007 to the summer of 2008 .

The first phase focused on students' first impressions of reading eBooks on a PPC. Six students were invited to participate in a number of sessions: introduction to the technology, guided hands on training with the hardware and software, and a guided reading session. Care has been taken to make sure the students:

- were from different disciplines;

- had no or very limited experience in using a PPC to read eBooks;

- were balanced in gender;

These sessions were followed by home reading for a week or two. At the same time, there was another group of four students who read a similar set of reading materials but in a paper based format. All students were asked to come back to do the same comprehension exercises after reading. Our interest was in identifying the potential of the technology as a useful learning tool. As mentioned, the students were from different programs. In most circumstances, the students met the researchers on a one to one basis. It seemed to be fair to assume that there was not much interaction among these students during the period.

In the second phase, another six students (referred to as Students 1 to 6 below) were invited to use eBooks in a more naturalistic fashion for an extended period of time (12 weeks). Our interest in this phase was to investigate the actual use of the technology as a learning tool. The criteria for student selection in this phase were the same as in the first phase (the six students were from these academic disciplines: psychology, medicine, accounting, information engineering, economics and chemistry). Each of them received on loan from the project a PPC for the reading tasks. Adobe Reader was the suggested PPC eBook reader to use. The PPCs involved were Mio DigiWalker P550, HP $i P A Q h \times 2400$ and HP $i P A Q h \times 2700$. The training was similar to that in the first phase. However, the post-training reading extended for about 50 hours over 12 weeks. The reading period was spread over four months and the students were advised to spread their reading load evenly over the period. The students were free to choose what they would like to read as long as they were academic books related to their own disciplines.

Through this two phase research design, we looked at two main issues concerning eBooks: usability and usefulness.

The usability issue relates to the practicality of the various procedures required to use the software and hardware, and the ease of use of the technology. It relates to issues such as interface design that facilitates effective human-computer interaction (Wilson et al., 2002). In this study, there are three sub-questions: 
1. Are eBooks easy to setup?

2. Are the functions easy to learn?

3. Are the functions easy to use?

The usefulness issue relates to whether eBooks can be effective learning tools. Similar to Morton et al. (2007), our focus is on the usefulness of the technology 'in education' (p. 56). In this study, the questions asked concerning usefulness included:

4. Do students enjoy the reading process?

5. Are students able to understand the digital text?

6. Are students willing to use eBooks in learning?

Multiple evaluation strategies were used, including:

- Pre-reading questionnaire: Students were asked to comment on the usability and perceived usefulness of the technology immediately after their training (prereading, phase 1; function-learning, phase 2).

- Researchers' observation records: A list of steps of using the NetLibrary and the PPC were set for students' learning at the pre-reading stage. The researchers recorded the questions asked and challenges observed during learning (pre-reading, function learning and reading, phase 1; function learning, phase 2).

- Video recording: The students' manipulations of the PPC and eBook readers were recorded during the reading sessions and were later coded by the researchers to reveal use patterns and moments of difficulties (function learning and reading, phase 1).

- Surveys: The student participants were asked on various occasions to rate, for example, the smoothness of the various procedures, their opinions on the usefulness of the functions and/or how much they enjoyed using eBooks, etc. (prereading preparation, function learning and reading, home reading, phase 1).

- Comprehension: Students' answers to a comprehension exercise at the end of reading were collected (function learning and reading, home reading, phase 1). The comprehension scores of the students who finished the home reading in phase 1 were also contrasted with the scores of the other four students who read similar text but on paper.

- Weblogs: Students were asked to write about their experience and comments in a weblog every week. No fixed structure was given and so students felt free to provide both positive and negative comments (extended reading, phase 2).

- Email/ phone consultation: Student could request help by phone or by email from the research team; these requests were recorded (extended reading, phase 2).

- Face to face interviews: The students were invited for face to face interviews every month and also for one at the end of the entire reading period (extended reading, phase 2).

- End of reading questionnaire: Students were asked to fill in a questionnaire (with both open ended and closed questions) after they had finished the project (home reading, phase 1 ; extended reading, phase 2 ).

Table 1 relates the various activities in phases 1 and 2 with the relevant research questions. 
Table 1: Sources of data related to the six research questions

\begin{tabular}{|l|c|c|c|c|c|c|}
\cline { 2 - 7 } & \multicolumn{3}{|c|}{ Useable? } & \multicolumn{3}{c|}{ Useful? } \\
\hline & $\begin{array}{c}\text { 1. Easy to } \\
\text { set up }\end{array}$ & $\begin{array}{c}\text { 2. Easy to } \\
\text { learn with }\end{array}$ & $\begin{array}{c}\text { 3. Easy to } \\
\text { use }\end{array}$ & 4. Enjoy & $\begin{array}{c}\text { 5. Under- } \\
\text { stand }\end{array}$ & $\begin{array}{c}\text { 6. Willing } \\
\text { to use }\end{array}$ \\
\hline Phase 1 pre-reading & $\checkmark$ & & & & & \\
\hline $\begin{array}{l}\text { Phase 1 function learning } \\
\text { and reading }\end{array}$ & & $\checkmark$ & $\checkmark$ & $\checkmark$ & $\checkmark$ & $\checkmark$ \\
\hline Phase 1 home reading & & & & $\checkmark$ & $\checkmark$ & $\checkmark$ \\
\hline Phase 2 function learning & $\checkmark$ & $\checkmark$ & & & & \\
\hline Phase 2 extended reading & & & $\checkmark$ & $\checkmark$ & $\checkmark$ & $\checkmark$ \\
\hline
\end{tabular}

\section{Findings}

\section{Are eBooks easy to setup?}

The six students who completed the pre-reading tasks in phase 1 were on the whole positive about the procedures required in order to set up the PPC to read eBooks. The six students in phase 2, however, had more complaints, especially during the time they had to do it repeatedly on their own.

Below are the procedures involved in the pre-reading setup:

a. Preparing the PC (including the installation of the PC eBook reader and the software that allows the PC to communicate with the PPC)

b. Preparing the PPC (including the installation of the PPC eBook reader (Adobe Reader), the actual connection with the PC, and the 'activation' of the PPC to tell the digital rights managing body (.Net in this case) that the PC and the PPC are licensed under the same user)

c. Finding and downloading an eBook (using the eBook library (NetLibrary in this case) search engine and borrowing a downloadable book through the system)

d. Transferring an eBook from the PC to the PPC (sending (synchronising) the downloaded eBook to the PPC for reading)

In the survey feedback from the phase 1 students, steps a., c. and d. were considered to be 'easy', with all the respondents responding either 'agreed' or 'strongly agreed' to the respective statements. Two of the students, however, found it difficult to complete step $\mathrm{b}$. Students elaborated on these difficulties in the follow up interviews. For example, the ActiveSync was not stable enough and sometimes the PPC could be detected only after the PPC was re-plugged. There was no indication about whether the PPC Adobe has been successfully activated. It was only later when they noticed a popup window displayed in the PC (not on the PPC), they could feel for sure they had completed the task successfully. Despite the difficulties, however, all students managed to complete all the steps (total time used ranged from 25 to 76 minutes). After the experience, all students agreed in the survey about feeling "confident that I can prepare and download eBooks on PPCs by myself". In the interview, they also remarked that the pre-reading setup was easy. At this stage, students were willing to use eBooks in the future.

In the training sessions of phase 2, the students could learn the procedures to use NetLibrary, download eBooks and transfer them to the PPCs. No significant problems were found. Minor problems were resolved on the spot. Students also seemed to have positive opinions of the technology at this stage as revealed in the pre-reading 
questionnaire they filled in right after the training. More problems arose, however, during the following weeks when the students were actually using the eBooks on their own and were using them more extensively. For example, the students mentioned the following challenges during the use in weblogs and / or in interviews.

- The eBooks expired after 24 hours: All eBooks downloaded from the NetLibrary expire after 24 hours. However, we discovered a way to 'fool' the expiry system so that students could still read an eBook after 24 hours. As the check for expiration takes place only when the eBook is closed, as long as the users keep the eBook open and do not close it, it can stay open indefinitely. Nevertheless, even though we had told the students the way to 'fool' the expiry system, there were still plenty of 'accidents' where the eBook was unintentionally closed. The following were the examples:

- The PPC of Student 1 had some system problems (backlight turned off unexpectedly) which were resolved by resetting the PPC. (Student 1)

- There were a number of occasions when the PPC power had run so low that it was automatically shut off. (Student 1 )

- The Adobe Reader shut down unintentionally. (Student 4)

- The Adobe Reader stopped running unexpectedly after the student minimised the window. (Student 2)

- Failure to download the eBook: Downloading the eBook from NetLibrary can be difficult. For example, Student 1 had a problem using her home computer to download any eBook. She and the research team spent a considerable time trying to fix the problem but failed. Finally, we used another computer to download the eBook for her. Student 4 also encountered a similar problem.

- Difficult to find a suitable eBook from the NetLibrary: The choice of eBooks in the NetLibrary is limited. Many comments concerning this problem were found in students' weblogs. The following are their comments:

- I was just so frustrated that I could not find any of the reference books listed in the course outline of the courses that I have taken. (Student 1)

- I spent 45 minutes on the NetLibrary searching for a suitable book. I tried numerous keywords, like medicine, skin, cancer, anatomy, etc. but I could not find a book I wanted to read. Most of them were either too specialised (beyond my scope of understanding) or the search results were completely not related to what I wanted. (Student 2)

- I tried to search other reference books from the net-library. At the same time, I searched through the web site of CU library. In my opinion, the books I found in $\mathrm{CU}$ library's web site was more suitable and useful. Those I found using netlibrary were just too advanced. (Student 4 )

- This week, I got to the netlibrary once and hoped to find a new ebook to read. But the volume of the netlibrary is really limited, I could not find the types of ebook which I was interested in. I searched for books about behavioral economics and currency market. Not many books were about behavioral economics and even I found one which was related to currency market, it could only be read online and was not able to download. (Student 5)

\section{Are the functions easy to learn?}

In general, students learnt the functions relatively easily. Table 2 illustrates the records of help needed (questions asked in the function learning sessions in phases 1 and 2). 
Students asked questions about the various features of using the eBook hardware and software, e.g. functions related to changing the display format, navigating through the text, manipulating the toolbar, searching within the eBook, and operating the PPC. Most of the problems recorded during the function learning processes were resolved on the spot.

Table 2: Learning and using the functions by students in the two phases

\begin{tabular}{|c|c|c|c|c|}
\hline \multirow[t]{2}{*}{ Operation } & \multicolumn{2}{|c|}{$\begin{array}{c}\text { Easy to learn? } \\
\text { (No. of students } \\
\text { needing help } \\
\text { during training) }\end{array}$} & \multicolumn{2}{|c|}{$\begin{array}{l}\text { Easy to use? } \\
\text { (No. of ongoing } \\
\text { challenges) }\end{array}$} \\
\hline & Phase 1 & Phase 2 & Phase 1 & Phase 2 \\
\hline Problem concerning changing the display format & 7 & 5 & 5 & \\
\hline $\begin{array}{l}\text { Read in the view such that no matter what the } \\
\text { magnification is, the text will be automatically } \\
\text { rearranged to fit the width of the document pane }\end{array}$ & 2 & 3 & 2 & \\
\hline Read in full screen mode & 3 & 1 & 3 & \\
\hline Rotate 90 degrees clockwise to read & 1 & & & \\
\hline $\begin{array}{l}\text { Reflow the passage whenever calling on the Default } \\
\text { Zoom function }\end{array}$ & 1 & & & \\
\hline Exit the full screen mode & & 1 & & \\
\hline Problem concerning navigation & 6 & & 4 & \\
\hline Jump to the next page & 1 & & & \\
\hline $\begin{array}{l}\text { Back to the last two pages you visited without typing } \\
\text { the page numbers }\end{array}$ & 2 & & & \\
\hline $\begin{array}{l}\text { Jump to the first page that contains a picture (except the } \\
\text { title page) }\end{array}$ & 1 & & & \\
\hline $\begin{array}{l}\text { Tap the bottom of the screen, instead of dragging and } \\
\text { scrolling, to proceed reading }\end{array}$ & 2 & & 1 & \\
\hline Problem concerning jump to page & & & 1 & \\
\hline Problem concerning the 'Back' function & & & 2 & \\
\hline Don't know how to add toolbar button & 4 & & 2 & \\
\hline Don't know how to add toolbar button & 2 & & 1 & \\
\hline Don't know that they should add a button & 2 & & 1 & \\
\hline Problem concerning searching & 2 & 4 & 2 & 2 \\
\hline $\begin{array}{l}\text { Search the words "They are", where capital "T" in the } \\
\text { word "They" is important, starting from the first page }\end{array}$ & 1 & 2 & & \\
\hline Search the word "an", starting from the first page & 1 & & & \\
\hline Don't know how to find the next searching result & & 1 & 1 & \\
\hline Misunderstand and misuse of searching functions & & 1 & 1 & \\
\hline Don't know the function of 'auto-scroll' & & & & 1 \\
\hline Don't know the function of 'bookmark' & & & & 1 \\
\hline Problem concerning basic operations of PPC & & 8 & & \\
\hline Check the free memory in PPC & & 2 & & \\
\hline Close unused program on PPC & & 4 & & \\
\hline $\begin{array}{l}\text { Display the viewing menu (similar to the right click of } \\
\text { mouse on PC) }\end{array}$ & & 2 & & \\
\hline Totals & 19 & 17 & 13 & 2 \\
\hline
\end{tabular}

\section{Are the functions easy to use?}

Table 2 (the last two columns) also shows the problems students had in using these functions after they had gone through the function reading sessions and during the time they actually read the eBooks on their own. In phase 1 , the data comes from 
observations in the one-hour reading period in the second half of the function learning and reading sessions. In phase 2 , the data is based on the email/ phone consultations, weblog entries and opinions collected in the interviews during the 12-week long reading period.

It can be seen that students in phase 1 seemed to have more problems in using the functions than those in phase 2. Taking into consideration that phase 1 students used these functions right after they had learnt about them while the phase 2 students were using them in a more extended timeframe, the difference between the two groups is easy to understand. The difference actually also suggests that many of these functions can be effectively self-learnt, given enough time, and so students in phase 2 did not need to resort to the researchers for help.

\section{Do students enjoy the reading process?}

In phase 1, the answers to this question are mainly based on the students' comments after students had done some reading in both the function learning and reading sessions, and the home reading sessions. In phase 2, students were asked about the whole reading process in many ways during and after the extended reading period.

In phase 1 , most students said the eBook reading process was enjoyable because it is convenient to read portable eBooks. Some commented that the novelty factor made it interesting. There were, however, some negative comments. Two students said their eyes were tired when reading eBooks, while two students mentioned limitations related to the hardware. One of them said that the eBook could only be read indoors because of lighting issues. A number of students told us that whether eBook reading is enjoyable depends on the content of the eBook. This suggests that success of eBooks rely on multiple factors: hardware, software and as well as the materials.

In phase 2, more negative comments were heard. Based on our conversations with the students in the interviews and the students' blog entries, we drew up a list of 19 existing characteristics (Table 3) that influence the perception of how useful the technology is for learning. At the end of reading questionnaire, these characteristics were listed for the students to rate: firstly, their opinion of how important the feature was for learning, and secondly, how satisfied they were about how these features worked. It may not be very meaningful to study features that were regarded as less important to the learning process. Thus, 10 features were identified (italics in Table 3). They were features that received an average score of above 4 (out of 5 ) in importance by the six students. The discussion below focuses mostly on these 10 features.

Many of these features that were regarded by the students as highly important were found by the students to be less satisfactory. Many of them had an average score of below ' 3 '. Students 1, 2 and 5 were particularly negative. They only complimented features $d$ (the PPC operates and reacts quickly (i.e. fast to open the files and to use the functions)) and $e$ (there are no restrictions of opening hours in NetLibrary). However, on the other hand, they rated a low score to many (five to seven) of the ten most important features. 
Table 3: Perception of importance and satisfaction of 19 characteristics of eBooks

\begin{tabular}{|c|c|c|}
\hline Features & \begin{tabular}{|c|} 
Importance \\
(scale of 5)
\end{tabular} & \begin{tabular}{|l} 
Satisfaction \\
(scale of 5)
\end{tabular} \\
\hline a. The usable time after charging up the PPC is long enough. & 4.5 & 2.7 \\
\hline$b$ The PPC (hardware) always works well. & 4.3 & 2.5 \\
\hline $\begin{array}{l}\text { c. NetLibrary has a large collection of academic eBooks that seem to be useful } \\
\text { to me. }\end{array}$ & 4.3 & 2.2 \\
\hline $\begin{array}{l}\text { d. The PPC operates and reacts quickly (i.e. fast to open the files and to use } \\
\text { the functions). }\end{array}$ & 4.3 & 3.8 \\
\hline e. There are no restrictions of opening hours in NetLibrary. & 4.3 & 4.3 \\
\hline f. The functions of Adobe Reader (PPC version) can always be used smoothly. & 4.2 & 3.5 \\
\hline g. The eBooks in the NetLibrary are of interest to me. & 4.2 & 2.0 \\
\hline $\begin{array}{l}\text { h. NetLibrary is a useful place to go for finding information related to my } \\
\text { study. }\end{array}$ & 4.2 & 2.2 \\
\hline i. The PPC screen is big enough for easy reading. & 4.2 & 2.5 \\
\hline j. The PPC is light in weight. & 4.2 & 4.0 \\
\hline k. The time required to charge up the PPC is appropriate. & 4.0 & 2.8 \\
\hline $\begin{array}{l}\text { 1. No traveling to the library is required if I borrow a book in } \\
\text { NetLibrary. }\end{array}$ & 4.0 & 4.2 \\
\hline m. It's convenient to renew the eBooks. & 4.0 & 2.5 \\
\hline n. I can comfortably use a PPC to read eBooks during travel. & 4.0 & 3.5 \\
\hline $\begin{array}{l}\text { o. It is easy to self-explore how to use the functions of Adobe Reader } \\
\text { (PPC version). }\end{array}$ & 3.8 & 3.2 \\
\hline $\begin{array}{l}\text { p. The functions provided by the Adobe Reader (PPC version) are } \\
\text { plentiful. }\end{array}$ & 3.8 & 2.7 \\
\hline q. The expiry date of an eBook in NetLibrary is long enough. & 3.8 & 2.2 \\
\hline $\begin{array}{l}\text { r. I can change the display format easily (e.g. rotate screen, change to } \\
\text { full screen mode, and reflow the page, etc). }\end{array}$ & 3.8 & 3.3 \\
\hline $\begin{array}{l}\text { s. Navigation is easy (e.g. jump to different pages, search for specific } \\
\text { information, and go to next and previous page, etc). }\end{array}$ & 3.2 & 3.0 \\
\hline
\end{tabular}

Their feedback from interviews and weblogs also echo the similar comments:

- The power level depleted fast that even the fully charged PPC was just left idle for one night, the power level would drop to a low level and the PPC could not be switched on (feature a, Student 5).

- The PPC needed to be charged very soon, as I saw the power level dropped quickly. Even when the power level was not very low (e.g. 40\%), I still had to charge it; otherwise I would risk the self-turning out of PPC (feature a, Student 1).

- The ppc turned off suddenly and it did not turn on again when i pressed the on button ... I was just so frustrated and angry!!! (feature b, Student 1).

- I spent 45 minutes on the elibrary searching for a suitable book. I tried numerous keywords, like medicine, skin, cancer, anatomy, etc. but I could not find a book I wanted to read. Most of them were either too specialised (beyond my scope of understanding) or the search results were completely not related to what I wanted (feature c, Student 2).

Even Students 3, 4 and 6, who were in general more positive about the technology, mentioned some problems in using the PPC.

- the adobe reader had been accidently shut down. I could no longer open the eBook I had downloaded before (feature b, Student 4).

- When I wanted to change to another eBook, I could hardly find one. Even when I found one, it was not downloadable (feature c, Student 6). 
- I do not like the small screen of the PPC because long sentences were cut into many short lines. I did not get used to move to the next line very often (feature i, Student 3).

Many students also complained that it was difficult to read pictures and graphics in eBooks (including the students who were generally positive about the use of the PPC). Students 1 and 2 mentioned in the interviews that pictures with fine details could not be displayed clearly on the small screen. Magnifying the picture showed the details but it also meant that much of the picture was beyond the boundary of the screen. Student 2 complained that not seeing the whole picture clearly at a glance was a significant drawback compared to a paper book. The difficulties of reading text and pictures also associated with a defect in the function of reflow (this function makes the text fit the width of the screen so that the user does not need to scroll the page horizontally). Student 6 mentioned in an interview that reading pictures was not convenient because the pictures could not be magnified when he used this function, and he had to stop using this function in order to magnify the pictures. Student 4 , who chose a computer book that contained some program codes with comments, told the researchers that after he had used this function, the comments overlapped with the program codes and made it unreadable.

When we compared the survey scores concerning enjoyment and comfort in using eBooks between the two groups of students, we found a large contrast (Table 4). Care is needed in our interpretation of the data, particularly in relation to the small number of students who were involved in the study. Nevertheless, the data served to indicate interesting patterns which can be the subject of future research. It seems that the more experience the students had with eBooks, the less they found the technology enjoyable and comfortable to use.

Table 4: General opinions of the students on eBook reading in phases 1 and 2

\begin{tabular}{|l|c|c|c|c|}
\hline \multirow{2}{*}{ Concepts measured } & \multicolumn{2}{c|}{ Phase 1 } & \multicolumn{2}{c|}{ Phase 2 } \\
\cline { 2 - 5 } & Mean & SD & Mean & SD \\
\hline Overall easiness of the eBook software functions & 4.8 & 0.3 & 3.3 & 0.8 \\
\hline Enjoyment of the eBook reading process. & 4.0 & 0 & 2.7 & 0.5 \\
\hline Comfort in reading on the PPC screen & 4.3 & 0.6 & 3.4 & 0.8 \\
\hline Assistance of eBook Reader features on reading & 4.0 & 0 & 3 & 0.7 \\
\hline Assistance of eBook Reader features on understanding & 4.0 & 0 & 3.2 & 0.7 \\
\hline Learnability of eBooks & 3.9 & 0.2 & 2.7 & 1.0 \\
\hline Future use of eBooks & 4.0 & 0 & 2.8 & 1.2 \\
\hline
\end{tabular}

\section{Are students able to understand the digital text?}

Data related to this question comes mainly from the students' performance on the comprehension exercises and their related comments after they had done some reading in both the function learning and reading sessions, and the home reading sessions in phase 1 . The mean percentage score on the comprehension exercise for the six students reading on a PPC was 47.7 (SD 14.3) and for the four students reading a paper book was 63.9 (SD 17.7). Statistical comparison is not sensible with this small sample size. Nevertheless, the scores were considerably higher among the students who read the paper based text and completed the same comprehension exercises than those who read the digital text. The finding is suggestive that reading in the digital format can be quite inefficient. 
In the interviews held after the phase 1 home reading sessions, the students noted that this inefficiency could be because they were not familiar with reading eBooks and concentrated less when reading eBooks. Besides, more time was spent processing the eBook content. A number of students said that they read eBooks more slowly than they read paper books. They said they were not familiar with eBook reading; their eyes would get tired easily when reading eBooks, and each reading session was quite short.

In phase 2, the students were asked to rate in the end of reading questionnaire whether they understand the content from reading text on a PPC versus reading text on paper. The mean score for reading on a PPC was 2.7 and for reading a paper book was 3.8.

\section{Do students use eBooks?}

Many of the students in phase 1 were attracted to the new technology, especially after having the first contact. They all said that they would be confident to use the NetLibrary to read eBooks. When they were asked if they would use the NetLibrary eBook in the future, many of their responses were quite positive too. Their reasons were that

- EBooks are portable.

- The system is convenient with no need to physically go to the Library to borrow books.

- Using the Adobe Reader, the information can be searched very quickly.

- There is a wide range of content related to academic and personal interests.

- This system may assist shortages of certain paper books in the Library.

- An eBook is good when it is not needed very frequently.

In phase 2, however, the situation was less promising after the students had long encounters with the new technology. First, the reading of eBooks during the four months did not entirely take place according to our expectations. Students 2, 3, 4, 5 and 6 were on the whole able to complete the required hours of eBook reading regularly and according to schedule, while Student 1 was just able to complete only about $55 \%$ of the required hours. However, that cannot be regarded as an indicator that students will use the eBooks without the present motivation of the research project (where they were paid as student helpers).

On the contrary, we have reason to believe that these students did not form a habit of using eBooks and would not be likely to continue using eBooks after this research study. For example, all the students were found to read only the minimum amount of reading as required by the project on the PPCs. If the students found the technology helpful, we would expect them to use it to read other non-required books as well. That just did not happen.

Negative opinions on using eBooks as a whole were also collected in the end of reading questionnaire and in the interviews / weblogs:

- ... this ppc is very troublesome!! I don't wanna say but I indeed start to hate it!! (Student 1)

- The PPC screen is reflective that was an annoying element that lower down my interest in reading the eBook. (Student 1)

- Overall, in these four months, I have found that I do not like using eBook. (Student 2) 
- I will use eBook only in the future when I am forced to do so (Student 5)

Lastly, evidence came from comparing the students' perception of eBooks in the two questionnaires they completed, one before the reading period and one after. Two of the students (Students 1 and 2) changed their perception of whether eBooks are effective for learning before and after the reading period. They had quite positive expectations about the technology before the reading period, but their view turned to negative in their answers to some similar questions after the reading period. Students 3 and 5 were still not very sure about the statement. Only Students 4 and 6 had found the technology promising.

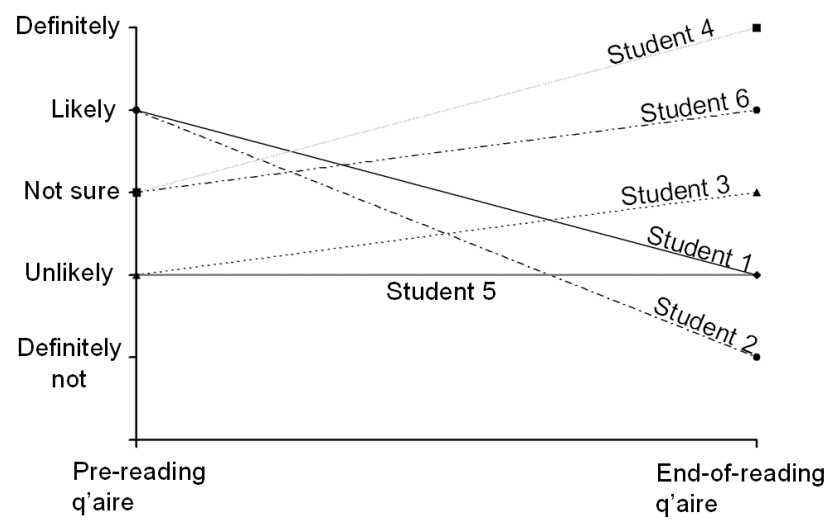

Figure 1: Changes of students' perception of eBooks about being an effective learning tool

In interviews, Student 4 said that an eBook is good if the paper version of the book is too thick. Student 6 thought he would choose eBook if it is a reference book and it needed to be carried around all the time. It is interesting to note that Student 4 is a student of Information Engineering and Student 6 is a Chemistry student. Judged by their disciplines, they may be more capable and comfortable with technology.

\section{Discussion and conclusion}

The experiences we had with the students indicated that eBooks are not yet a useful and practical tool for academic learning. Enjoyment of the eBook reading process was not high. Comprehension of digital text was also found to be challenging. It is very interesting to observe that students who gave us their first impression (phase 1 students) regarded the technology more positively than those who spent more time on it (e.g. phase 2 students). We also found that students' backgrounds seem to affect their use and opinions of eBooks. In phase 2, students who were studying science or engineering seemed to be able to feel better about the technology after the long period of use and could overcome small technical and procedural challenges, while those less comfortable with technology may feel distressed. Clearly user support is vital.

Many of the features and functions are available in the eBook software seem to be easy to learn and use. However, there are concerns with the various other aspects of the technology (such as the NetLibrary, the processes of finding and downloading the eBooks, the hardware, and the reading process itself), and these in turn had negatively 
impacted on students' views about its usability, usefulness and the likelihood they would actively use the technology. The lesson is that the success of the technology as an effective learning tool relies on every aspect of the technology working well.

The setup procedures are cumbersome and difficult. They put unnecessary stress on students who use the technology often and who are not particularly comfortable with computers. The process of downloading and then transferring the eBooks to the PPCs is also not straightforward. The Adobe Reader and PPC are not stable and sometimes lead to unexplained failures (for example, what happened to Student 1 in phase 2). The authentication process that is required before eBooks from a PC can be transferred to a PPC is also problematic.

The short loan period decreases the overall practicality of the technology. A more comprehensive set of book titles is also necessary. Although not mentioned by the students in this study, as each of the six students in phase 2 read a different book, we realised that there are only a certain number of copies available for loan by students in a given institution, limiting the value of eBooks as required texts. All these points may well be addressed as the system matures.

The functions and features of the software can be further improved too. The students in phase 2 mentioned some new features they thought would be very useful to their eBook experience. Additional new functions that suggested were the functions for jotting down notes and/or highlighting text; these are very important reading strategies for our students (for whom English is a second language), particularly when they are reading academic books. Other areas such as navigation of lengthy text and viewing large images need improvement. Also, students wish to download the eBook directly from NetLibrary to the PPC, rather than via a PC.

The current PPC hardware has limitations which inhibit reading. The small screen restricted students from scanning through the whole page, and thus slowed down their reading speeds. More importantly, viewing diagrams and images is difficult. The power supply also depletes quite rapidly. Students needed to charge the battery very frequently and this process also takes a long time. The PPC can be unstable, as in the case of Student 1 who had a malfunctioning of the device's backlighting.

Despite the negative opinions of the students about eBook technology, we should not be too pessimistic about the strategy yet. Advantages of eBooks are also obvious from our study of the students' reading habits. Portability is certainly a very important strength for eBooks. The students told us that much of the eBook reading was done during their travel to and from the University. If they were reading a large paper book, they would find it too heavy to carry around and too cumbersome to open for reading in public transport. One student commented that she could carry dozens of eBooks with no additional weight.

We are aware of the limitation of this study in that the number of subjects was small. Future investigations should include more students in authentic learning environments - that is, within the context of actual courses. At this stage at CUHK, teachers give eBooks as references in courses but not as primary references, for the reasons explained above. Overall, we consider eBooks to be a technology still in a developmental phase. 


\section{Acknowledgment}

Funding support from the University Grants Committee in Hong Kong is gratefully acknowledged.

\section{References}

Cavanaugh, T. \& Cavanaugh, C. (2008). eBook libraries (The whole list). http://drscavanaugh.org/ebooks/libraries/ebook_libraries_list.htm [viewed 29 Jul 2008].

Ching, H. S., Poon, P. W. T. \& McNaught, C. (Eds.) (2006). eLearning and digital publishing. Dordrecht: Springer.

Hernon, P., Hopper, R., Leach, M. R., Saunders, L. L. \& Zhang, J. (2006). E-book use by students: Undergraduates in economics, literature and nursing. The Journal of Academic Librarianship, 33(1), 3-13.

Lam, P., Lam, J. \& McNaught, C. (in press). How usable are eBooks in an mLearning environment? International Journal of Web Based Communities (IJWBC).

Lemken, B. (1999). Ebook: The missing link between paper and screen. Designing Electronic Books Workshop. In Proceedings of the ACM CHI99 Conference on Human Factors in Computing Systems. Pittsburgh, PA.

Leung, C. H., Chan, Y. Y. \& Chan, C. S. C. (2003). Analysis of mobile commerce market in Hong Kong. ACM International Conference Proceeding Series, 50, 408-412. Pittsburgh, Pennsylvania.

Malama, C., Landoni, M. \& Wilson, R. (2004). Fiction electronic books: A usability study. Eighth European Conference on Research and Advanced Technology for Digital Libraries, Bath, 12-17 Sep. http:/ / www.springerlink.com/ content/nehrdgnk1b8wj9vq/fulltext.pdf [viewed 29 Jul 2008].

Morton, D. A., Foreman, K. B., Goede, P. A., Bezzant, J. L. \& Albertine, K. H. (2007). TK3 eBook software to author, distribute, and use electronic course content for medical education. Advances in Physiological Education, 31, 55-61.

NetLibrary. http:/ / www.netlibrary.com/ [viewed 29 Jul 2008].

Rao, S. S. (2003). Electronic books: A review and evaluation. Library Hi Tech, 27(1), 85-93.

Rogers, E. M. (2003). Diffusion of innovations (5th ed.), New York: Free Press.

Shiratuddin, N., Landoni, M., Gibb, F. \& Hassan, S. (2003). E-book technology and its potential applications in distance education. Journal of Digital Information, 3(4). [viewed 29 Jul 2008] http:/ / jodi.tamu.edu/Articles/v03/i04/Shiratuddin /

Simon, E. J. (2002). An experiment using electronic books in the classroom. Journal of Computers in Mathematics and Science Teaching, 21(1), 53-66.

Wilson, R. (2003). Ebook readers in higher education. Educational Technology E Society, 6(4), 8-17. http://www.ifets.info/journals/6_4/3.pdf

Wilson, R., Landoni, M. \& Gibb, F. (2002). Guidelines for designing electronic books. Sixth European Conference on Research and Advanced Technology for Digital Libraries (ECDL 2002), Rome, 16-18 September. [viewed 29 Jul 2008] http:/ / www.cis.strath.ac.uk/research/publications / papers/strath_cis_publication_27.pdf 
This article received an Outstanding Paper Award at ascilite Melbourne 2008 Conference, gaining the additional recognition of republication with minor corrections in AJET. The reference for the Conference version is:

Lam, P., Lam, S. L., Lam, J. \& McNaught, C. (2008). Usability and usefulness of eBooks on PPCs: How students' opinions vary over time. In Hello! Where are you in the landscape of educational technology? Proceedings ascilite Melbourne 2008. http:/ / www.ascilite.org.au/conferences/melbourne08/procs/lam.pdf

Paul Lam, Shun Leung Lam, John Lam \& Carmel McNaught

Centre for Learning Enhancement And Research (CLEAR)

The Chinese University of Hong Kong, Shatin, Hong Kong

Further details at http:/ / www.cuhk.edu.hk/ clear/

Contact author: paul.lam@cuhk.edu.hk 